\title{
Behavior of Steel-Concrete Composite Beams with Corroded Shear Studs Under Negative Bending Moment
}

\author{
J. Chen, A. Jiang, and W. Jin \\ Department of Civil Engineering, Zhejiang University
}

\begin{abstract}
The behavior of corroded steel-concrete composite beams under hogging moment was studied by experimental investigation and theoretical analysis. A total of eight specimens, six of which had corroded shear studs, were tested. The corrosion rate of studs ranged from 0 to approximately $50 \%$. The constant-current accelerated corrosion method was adopted to accelerate the corrosion process. The loading test results indicated that the bending capacity of the corroded beams decreased slightly with increasing corrosion ratio of the studs. The corroded beams also exhibited an obvious decrease in bending rigid stiffness and increase in the slip between the steel beam and the concrete slab. An analytical model was developed to study the steel-concrete composite beams with corroded studs under hogging moment. It is shown that the analytical model is able to predict the test results with reasonable accuracy.
\end{abstract}

Keywords: analytical model, corroded stud, hogging moment, steel-concrete composite beam.

\section{INTRODUCTION}

Steel-concrete composite beams are widely used in building and bridge constructions because of the satisfactory utilization of the two materials, steel and concrete. However, an unfavorable condition, in which the concrete is in tension and the steel is in compression, occurs in practical structures, such as continuous beams in multistory buildings and longspan bridges. When a concrete slab is in tension and a lower flange of a steel girder is in compression under hogging moments, there are shortcomings from the point of view of durability and strength. Concrete cracking in the slab affects the durability and service life of structures (Navarro \& Lebet, 2001; Ramm \& Elz, 1996; Ryu, Chang, Kim, \& Kim, 2005). Corrosion will occur at the studs of the composite beams. A large number of research works have been devoted to the analysis of composite beams under hogging moment (Fabbrocino, Manfredi, \& Cosenza, 2000; Liang, Uy, Bradford, \& Ronagh, 2004; Manfredi, Fabbrocino, \& Cosenza, 1999), which are mainly focused on the ultimate capacity of the composite beams under hogging moment and the crack propagation in concrete slabs (Loh, Uy, \& Bradford, 2004; Nie, Cai, \& Wang, 2005; Nie, Fan, \& Cai, 2008; Wang, 1998). However, no work has been reported on the behavior of corroded composite beams under hogging moment. In this study, an experimental investigation was conducted on corroded composite beams subjected to hogging moment. A total of eight specimens, six of which had stud shear connector corrosion ratios ranging from 10 to $60 \%$ and two control specimens, were tested.
An analytical model was used to study the behavior of composite beams under hogging moment (Manfredi et al., 1999). The developed model is very useful to understand the behavior of a composite beam under hogging moment. An analytical model was also developed in this study, which is able to consider the corrosion of studs. The model predictions are verified against the test results.

\section{TEST PROGRAM}

A total of eight steel-concrete composite beams were tested. All steel girders were welded using steel plates of grade Q345. Stiffening ribs were set at the load points and support points for all the specimens. A 450-mm-wide, 70-mm-thick, and 1900-mm-long concrete slab was compositely connected to the steel bottom flange by means of shear studs for all the specimens. Full shear connection was achieved in accordance with Eurocode 4 (2004). The details of the specimens are given in Figure 1.

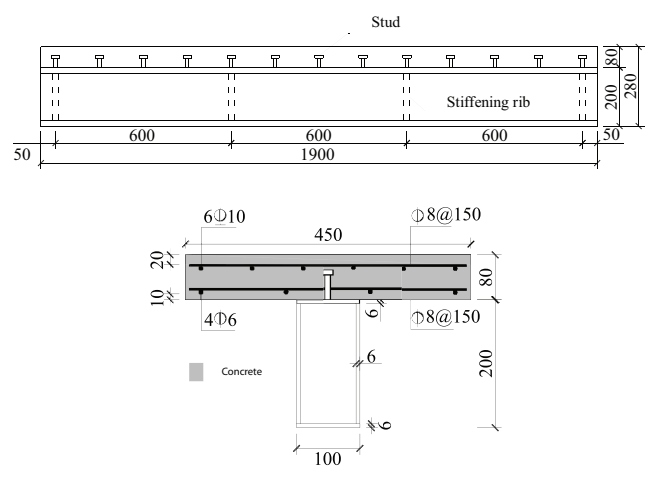

Figure 1. Dimensions of the composite beam test specimens. 
Tensile test coupons cut from the webs of the steel beam were tested to obtain the steel's material properties. The average values obtained from the test for the modulus of elasticity and yield stress were 201,900 and 333.6 MPa, respectively. The ultimate strength was $478.7 \mathrm{MPa}$. The yield stress of reinforcing bars with diameters of 6,8 , and $10 \mathrm{~mm}$ was 298.5, 427.3, and 447.6 MPa, respectively. The yield strength of the studs was $462.7 \mathrm{MPa}$. The average compressive strength determined by tests on a cube $\left(f_{\text {cu }}\right)$ of concrete was 47.5 MPa.

All specimens, except the uncorroded one, were immersed in a $5 \% \mathrm{NaCl}$ solution for 3 days and cured for 28 days, and then a direct current of about $0.2 \mu \mathrm{A} /$ $\mathrm{cm}^{2}$ was applied for accelerating stud corrosion; the studs worked as the anodes, while a piece of stainless steel positioned in the solution served as the cathode. The "I" section steel beam was isolated by epoxy resins so that corrosion occurred only on the stud and the steel-concrete interface. The corrosion time of each specimen was determined based on the expected corrosion rate. Faraday's law was used to calculate the expected corrosion time. It should be noted that the actual corrosion rates of the test specimens might differ from the expected corrosion rates.

The beam was simply supported on rollers, and a load was applied to the steel beam of the composite by means of a spreader. Each span of the beams was $1900 \mathrm{~mm}$, with a $50 \mathrm{~mm}$ extended portion overhang at each edge support. Figure 2 shows the test setup. The load was slowly applied and monotonically increased until failure after some unloading-reloading cycles in the elastic domain. The deflections were measured by linear variable displacement transducers located underneath the concrete slab at mid-span and onethird span on each side of the specimens. Two dial indicators were used to measure the slip between the steel beam and concrete slab at each end of the beam. The details of the instrumentation are given in Figure 3.

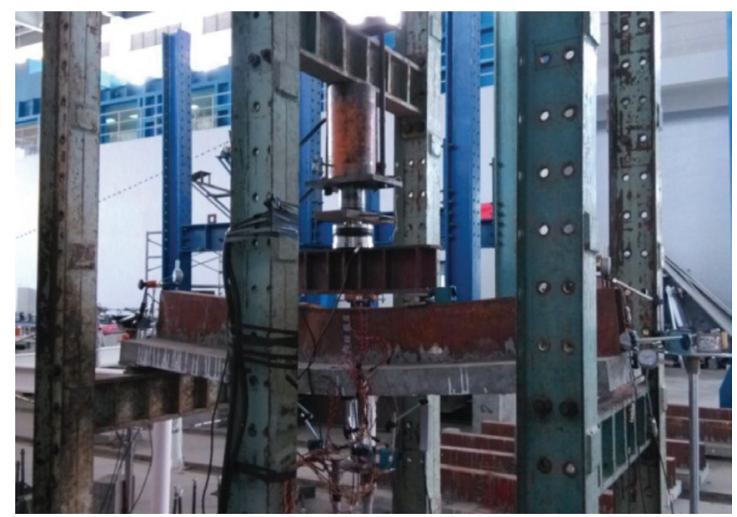

Figure 2. Load test setup.

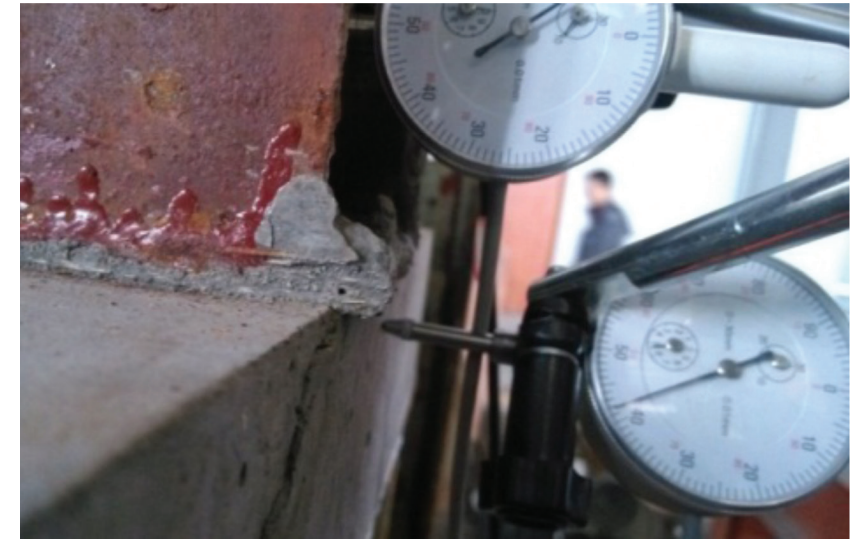

Figure 3. Dial indicator for slip measurement.

\section{TEST RESULTS}

The corroded studs were retrieved from the failed specimens, and the corrosion product was cleaned using a corrosion-inhibited $\mathrm{HCl}$ solution (Bertoa, Simionib, \& Saettab, 2008). The area loss of the steel rebar $(\Delta)$ was estimated afterwards by subtracting the post-corrosion area from the measured pre-corrosion area. The post-corrosion area of a stud was calculated using the measured diameter of the shank of the stud. The measured diameter of the shank was used to calculate the corrosion rate of each stud $(\psi)$ as: $\psi=(A-\Delta A) / A \%$. The average corrosion rate of 13 studs was taken as the value of each test specimen. It is seen that the measured corrosion rates of the test specimens are different from the expected corrosion rates, as shown in Table 1.

Table 1. Measured corrosion rate of studs.

\begin{tabular}{lcc}
\hline Test specimens & Expected $\psi(\%)$ & Measured $\psi(\%)$ \\
\hline CB10 & 10 & 6.5 \\
CB20 & 20 & 16.4 \\
CB30 & 30 & 19.6 \\
CB40 & 40 & 30.0 \\
CB50 & 50 & 42.7 \\
CB60 & 60 & 49.7 \\
\hline
\end{tabular}

The failure mode and the ultimate strengths are presented in comparison with the analytical results in Table 2. The final failure modes were the same for all test specimens. All specimens failed due to shear stud failure, as shown Figure 4. The load-deflection curves of the test specimens are presented in Figure 5. It is seen that the stiffness of the composite beams decreases when the stud corrosion rate increases. The load-slip (slip between steel beam and concrete slab) curves are presented in Figure 6. In general, the slip increases with increasing stud corrosion rate. 


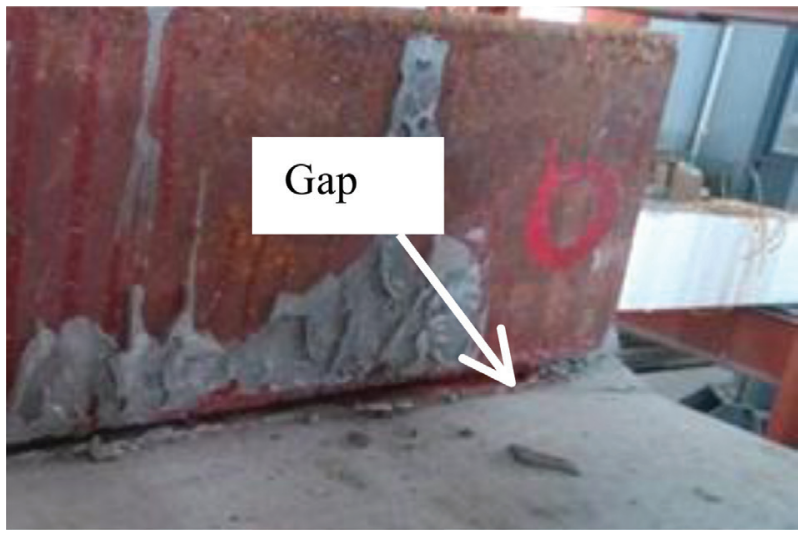

Figure 4. Shear stud failure of specimen CB10.

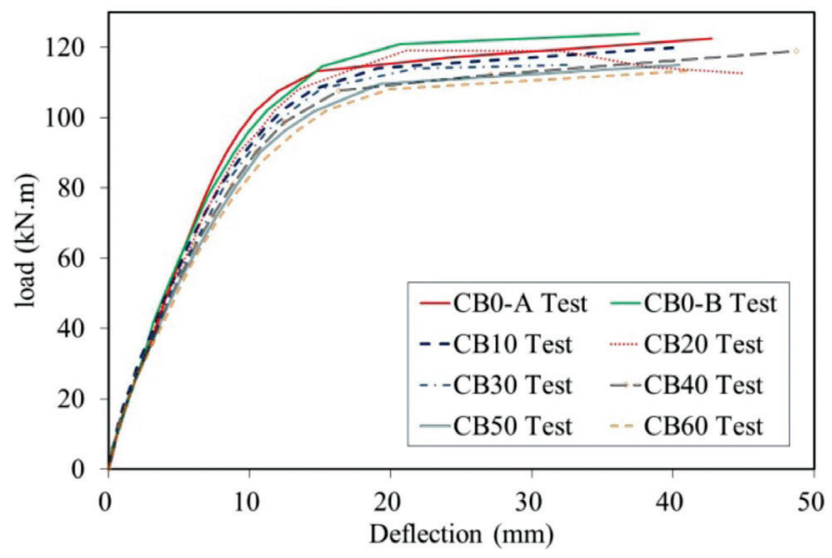

Figure 5. Load-deflection curves of test specimens.

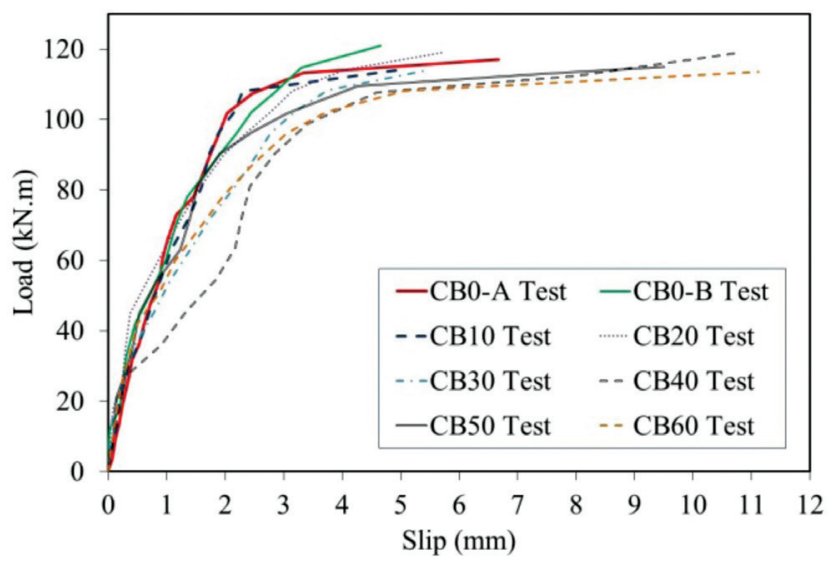

Figure 6. Load-slip curves of test specimens.

\section{ANALYTICAL MODEL}

An analytical model was established to study the composite beam with the corroded shear studs under hogging moment. The analytical model was developed based on the model proposed by Manfredi et al. (1999). Modification of the model was made based on the test results in this study.

\subsection{Hypotheses}

(1) Original plane cross-sections of steel beam and concrete slab remain plane; this assumption must be applied separately to the two parts of the composite section (steel beam and concrete slab).

(2) The two parts of the composite beam have the same rotation and the same curvature.

(3) Slip can occur at the concrete slab and steel beam interface as well as at the reinforcing bar and concrete interface.

(4) The concrete between two subsequent cracks is able to bear tensile stresses. The concrete in tension is limited to the so-called effective area $A_{\text {eff }}$ The height of the effective area is assumed as $2 a_{\mathrm{s}}$ in this study.

(5) The generic uncracked section is characterized by a linear distribution of the axial strain, limited to the concrete in compression and the reinforcing bars in tension.

(6) The concrete slab is cracked, and the distance between cracks depends on the spacing of transverse reinforcing bar, as observed in the test.

\subsection{Displacement and strain}

Figure 7 shows the references axes $(x, y, z)$ of a composite beam. The distribution of the axial displacements for a given section can be expressed by the function $w(x, y)$. Thus the displacement of steel beam $w_{s}(y, z)$, concrete slab $w_{c}(y, z)$, and longitudinal reinforcing bar $w_{\mathrm{sb}}(z)$ can be calculated using Equations (1)-(3), respectively:

$$
\begin{gathered}
w_{s}(y, z)=w_{s}(0, z)+y \tan \varphi \\
w_{c}(y, z)=w_{c}\left(h_{1}, z\right)+\left(y-h_{1}\right) \tan \varphi \\
w_{s b}(z)=w_{c}\left(h-a_{s}, z\right)
\end{gathered}
$$

The displacement corresponding to the effective area of concrete in tension is expressed as $w_{\mathrm{ct}}(z)$.

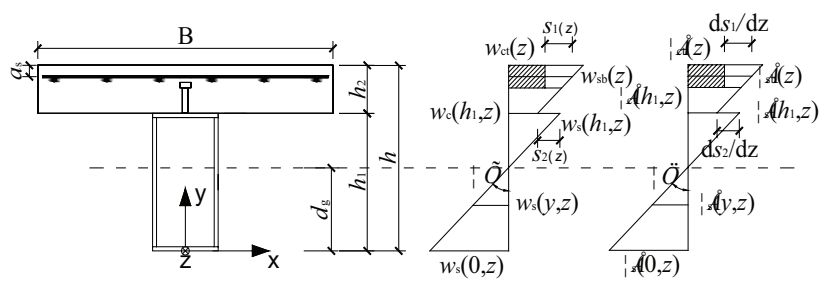

Figure 7. Schematic representations of the analytical model. 
The two slips are given by Equations (4) and (5):

$$
\begin{gathered}
s_{1}(z)=w_{s b}(z)-w_{c t}(z) \\
s_{2}(z)=w_{s}\left(h_{1}, z\right)-w_{c}\left(h_{1}, z\right)
\end{gathered}
$$

The axial strains of the composite beam section can be expressed as Equation (6):

$$
\begin{gathered}
\varepsilon_{s}(y, z)=\frac{d w_{s}(y, z)}{d z} \\
\varepsilon_{c}(y, z)=\frac{d w_{c}(y, z)}{d z} \\
\varepsilon_{s b}(z)=\frac{d w_{s b}(z)}{d z} \\
\varepsilon_{c t}(z)=\frac{d w_{c t}(z)}{d z}
\end{gathered}
$$

where $\varepsilon_{s}(y, z)$ is the strain of steel beam, $\varepsilon_{c}(y, z)$ is the strain of concrete slab, $\varepsilon_{\mathrm{sb}}(z)$ is the strain of the longitudinal reinforcing bar, and $\varepsilon_{\mathrm{ct}}(z)$ is the strain of the concrete in tension.

\subsection{Equilibrium equations}

The force equilibrium equation and moment equilibrium equation of the composite beam can be established as follows:

$$
\begin{gathered}
F_{c}(z)=-F_{s}(z) \\
F_{c}(z)=\int_{A_{c t}} \sigma_{c t}(y, z) d A+N_{r} \sigma_{s b}(z) A_{s b} \\
F_{s}(z)=\int_{A_{s}} \sigma_{s}(y, z) d A
\end{gathered}
$$

The resulting force on the reinforcing bar and the concrete slab equals the shear force transferred from the studs. Thus Equation (10) is established:

$$
F_{c}(z)=\sum F_{j}
$$

where $F_{j}$ is the shear force transferred by the $j$ th stud.

The moment equilibrium equation of the composite beam section can be described as Equation (11):

$$
\begin{aligned}
M(z)= & \int_{A_{s}} \sigma_{s}(y, z)\left(y-d_{g}\right) d A \\
& +\int_{A_{c t}} \sigma_{c t}(z)\left(y-d_{g}\right) d A \\
& +N_{r} \sigma_{s b}(z) A_{s b}\left(h-a_{s}-d_{g}\right)
\end{aligned}
$$

where $d_{g}$ is the height of the neutral axis.
The tensile stress in the longitudinal reinforcing bar is transferred from the bond stress between the concrete and reinforcing bar, as described in Equations (12) and (13):

$$
\begin{gathered}
\frac{d \sigma_{s b}(z)}{d z}=\frac{4 \tau_{s b}(z)}{D_{r}} \\
\frac{d \sigma_{c t}(z)}{d z}=\frac{n \pi D_{r} \tau_{s b}(z)}{2 B a_{s}}
\end{gathered}
$$

where $B$ is the width of the concrete slab and $D_{r}$ is the diameter of reinforcing bar.

The slip strain between the longitudinal reinforcing bar and concrete can be described as Equation (14) and the slip strain between the steel beam and the concrete slab as Equation (15):

$$
\begin{gathered}
\frac{d s_{1}(z)}{d z}=\varepsilon_{s b}(z)-\varepsilon_{c t}(z) \\
\frac{d s_{2}(z)}{d z}=\varepsilon_{s}\left(h_{1}, z\right)-\varepsilon_{c}\left(h_{1}, z\right)
\end{gathered}
$$

\subsection{Material properties}

For the reinforcing bar and steel beam, the measured stress-strain curves obtained from the tensile coupon tests were used. For concrete, a concrete constitutive law proposed by Balakrishnan and Murray (1988) was used. A bond-slip model between the reinforcing bar and the concrete, specified in the CEB-FIP (1998), was used in this study. For the corroded stud, the force-slip curves obtained from the corroded push-out test were used (Jiang, 2014).

\subsection{Equation solution}

The whole composite beam was first divided into $n$ ( $n=12$ in this study) elements by the spacing of studs, as shown in Figure 8. Each element was further divided into $N(N=30$ in this study) subelements. For each subelement, the force equilibrium equation and moment equilibrium equation should be satisfied.
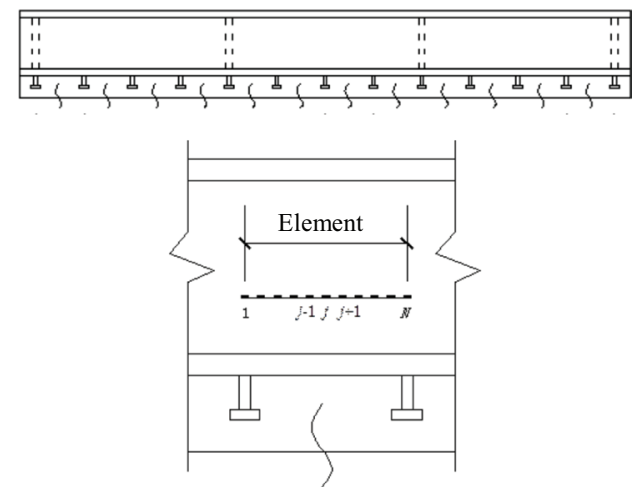

Figure 8. Element mesh of the analytical model. 
First, an initial value of slip of the first subelement of the first element $\left(s_{2,1}(1)\right)$ is assumed, which is also the slip of the first stud. Thus, the shear force $\left(F_{1}\right)$ transferred by the stud could be obtained. Then the resultant force in concrete and reinforcing bar could be obtained according to Equation (10). At the position of a crack in the concrete slab, namely 15 th and 16 th subelements, cracking transfers the whole force to the reinforcement, and the force of the reinforcing bar in those two subelements is $F_{1}$. Given the applied moment on the 15th and 16th subelements, the stress and strain of those two subelements could be calculated using Equation (14).

Assuming a slip value $s_{1,15}(1)$ between the reinforcing bar and concrete for the 15th subelement, the bond stress $T_{\mathrm{sb}, 15}(1)$ between the concrete and the longitudinal reinforcing bar could be obtained with the CEB-FIP (1998) model. Then the force of the reinforcing bar and concrete of the 14th subelement could be calculated with Equations (16) and (17), respectively. The stress and strain of the 14th subelement could be calculated using Equation (11). Following this procedure, the stress, strain, and slip between reinforcing bar and concrete of the 14th to the first subelements could be calculated. As mentioned above, the slip between the reinforcing bar and concrete of the first subelement should be zero. This is the convergence condition for the iteration of the assumed value of $s_{1,15}(1)$.

$$
\begin{array}{r}
\sigma_{s b, i}(j-1)=\sigma_{s b, i}(j)-\frac{4 \tau_{s b, i}(j-1) \Delta z}{D_{r}} \\
\sigma_{c t, i}(j-1)=\sigma_{c t, i}(j)+\frac{n \pi D_{r} \tau_{s b, i}(j-1) \Delta z}{2 B a_{s}}
\end{array}
$$

For the 16th to 30th subelements, the same procedure was used to calculate the strain and stress of those subelements. Thus the slip of the 30th subelement of the first element $\left(s_{2,1}(30)\right)$ could be obtained, which is the difference between the strain of the steel beam's bottom fiber and the strain of the concrete slab's top fiber of the 30th subelement. With the existence of the stud, the slip of the 30th subelement of the first element $\left(s_{2,1}(30)\right)$ is considered the same as the slip of the first subelement of the second element $\left(s_{2,2}(1)\right)$. Thus the shear force transferred by the second stud $\left(F_{2}\right)$ could be obtained. Following the procedure for the first element above, the stress and strain of all subelements of the second element could be calculated.

Then the stress, strain, slip between the steel beam and concrete slab, and slip between the longitudinal reinforcing bar and concrete of each element could be calculated. The slip between the steel beam and concrete slab at the mid-span of the composite beam should be zero because of symmetry. This is the convergence condition for the iteration of the assumed value $s_{2,1}(1)$.

\section{COMPARISON WITH TEST RESULTS}

The test results of the failure mode, ultimate strength, load-deflection curves, load-slip curves, and maximum crack width were compared with the model predictions.

\subsection{Failure mode and ultimate strength}

The failure mode and ultimate strengths of the composite beams obtained from the analytical model analysis and test results are compared in Table 2. The comparison indicates that the analytical model is able to predict the failure mode and ultimate strengths of the test specimen reasonably accurately. The failure mode of all test specimens is stud failure, which is accurately predicted by the analytical model. For the ultimate strength, the model predictions are slightly conservative compared with the test results. The mean value of $\left(M_{\text {Aly }} / M_{\text {Test }}\right)$ is 0.98 with the corresponding coefficient of variance (COV) of 0.011 .

Table 2. Comparison of failure mode and ultimate strengths.

\begin{tabular}{lcccccc}
\hline Specimens & $\begin{array}{c}\boldsymbol{\Psi} \\
(\%)\end{array}$ & $\begin{array}{c}\boldsymbol{M}_{\text {test }} \\
(\mathbf{k N m})\end{array}$ & $\begin{array}{c}\text { Failure } \\
\text { mode }\end{array}$ & $\begin{array}{c}\boldsymbol{M}_{\text {Aly }} \\
(\mathbf{k N m})\end{array}$ & $\begin{array}{c}\text { Failure } \\
\text { mode }\end{array}$ & $\begin{array}{c}\boldsymbol{M}_{\text {Aly }}{ }^{\prime} \\
\boldsymbol{M}_{\text {test }}\end{array}$ \\
\hline CB0-A & 0 & 122.4 & SF & 119.9 & SF & 0.98 \\
CB0-B & 0 & 123.9 & SF & 119.9 & SF & 0.97 \\
CB10 & 6.1 & 120.0 & SF & 118.3 & SF & 0.99 \\
CB20 & 16.4 & 119.1 & SF & 117.3 & SF & 0.99 \\
CB30 & 19.6 & 117.3 & SF & 116.2 & SF & 0.99 \\
CB40 & 30.0 & 118.8 & SF & 114.0 & SF & 0.96 \\
CB50 & 42.7 & 115.8 & SF & 111.7 & SF & 0.96 \\
CB60 & 49.7 & 113.4 & SF & 110.1 & SF & 0.97 \\
& & & & Mean & & 0.98 \\
& & & & COV & & 0.011 \\
\hline
\end{tabular}

Note: SF, stud failure.

\subsection{Load-deflection curves and load-slip curves}

The load-deflection curves of the test specimens are compared with the analytical model's prediction in Figure 9. It is seen that the analytical model closely predicts the load-deflection curves except that the test specimens are more ductile. This is because the analysis of the model stopped when any stud failed. However, the deflection could further develop in the test although the load had no obvious increase.

The load-slip curves of the test specimens are compared with the analytical model predictions in Figure 10. The slip between the steel beam and concrete slab was measured at the end of the composite beam which is the position of maximum slip along the beam length. In general, it is seen that the 


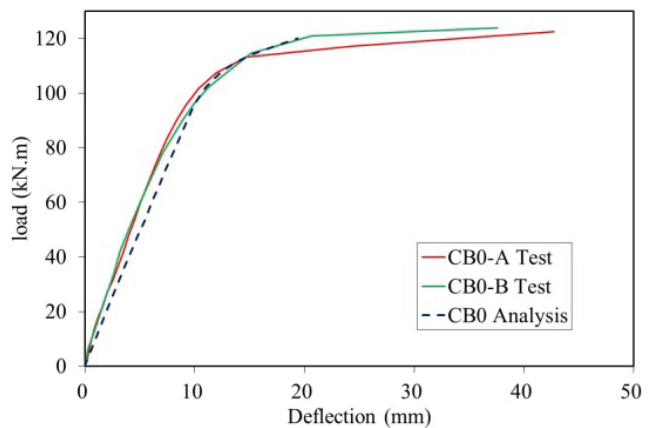

(a) CB0

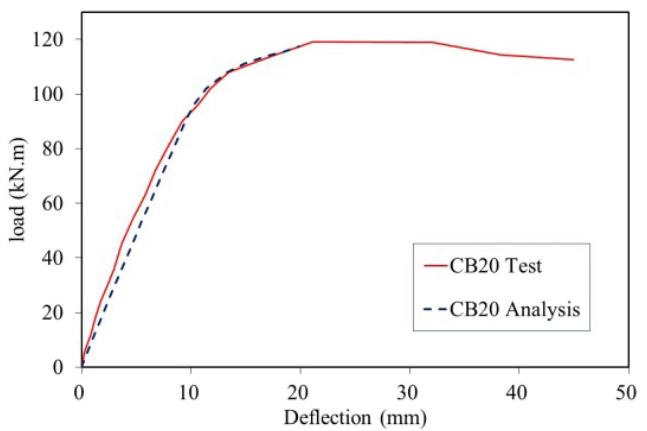

(c) CB20

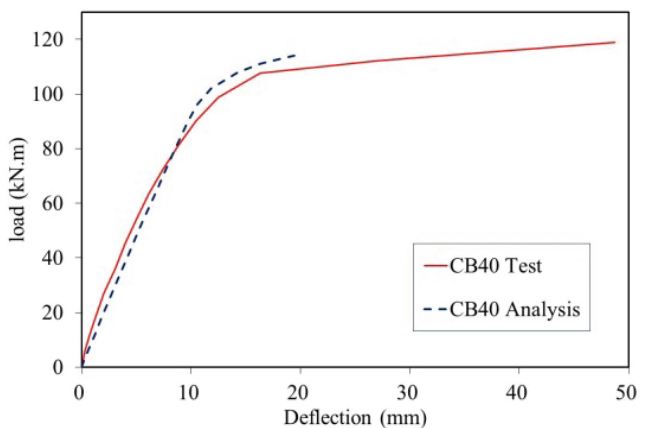

(e) CB40

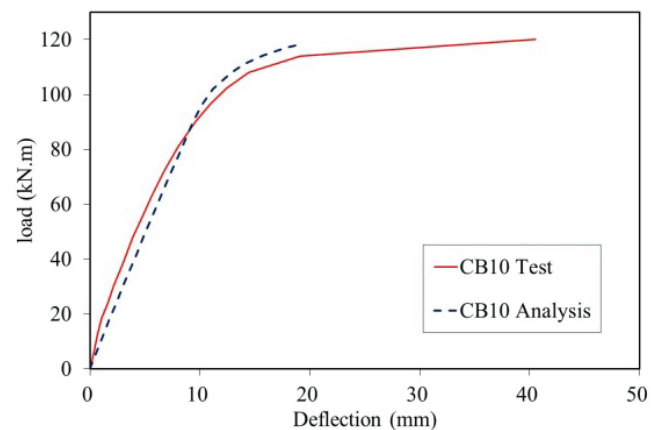

(b) CB10

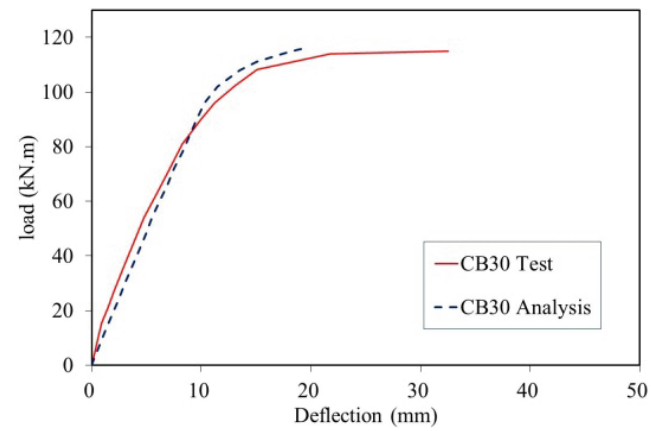

(d) CB30

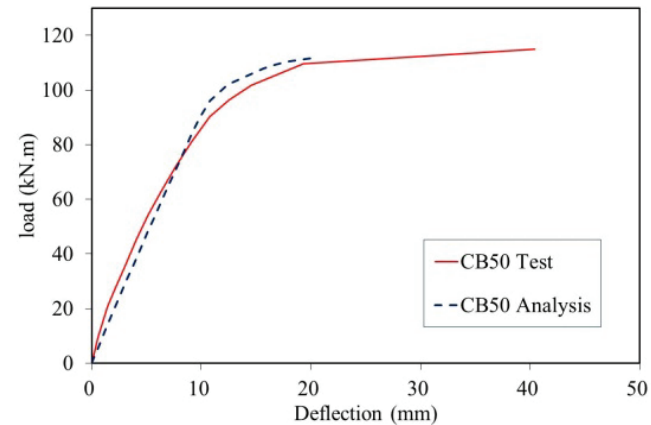

(f) $\mathrm{CB} 50$

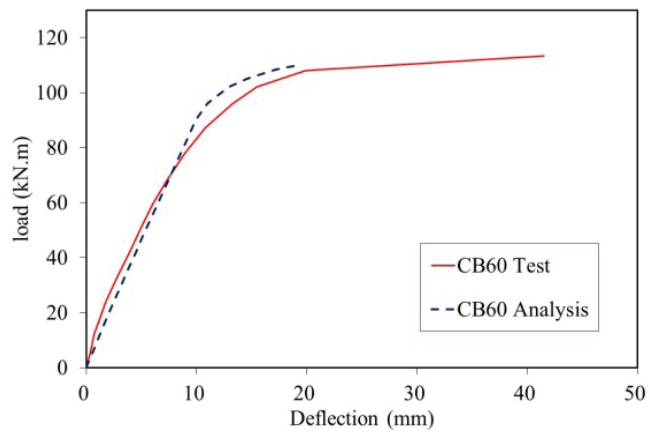

(g) CB60

Figure 9. Comparison of the load-deflection curves.

analytical model predictions agree well with the test results. There is some difference between the initial part of the analytical curve and the test results. The difference gradually reduced when the slip developed. It may be explained by the fact that the initial slip values were difficult to measure accurately. 


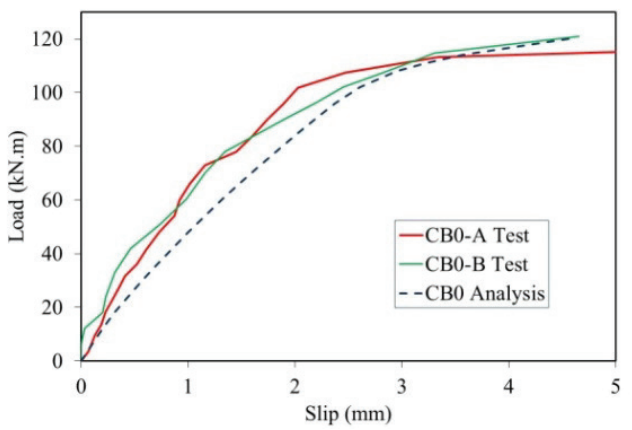

(a) CB0

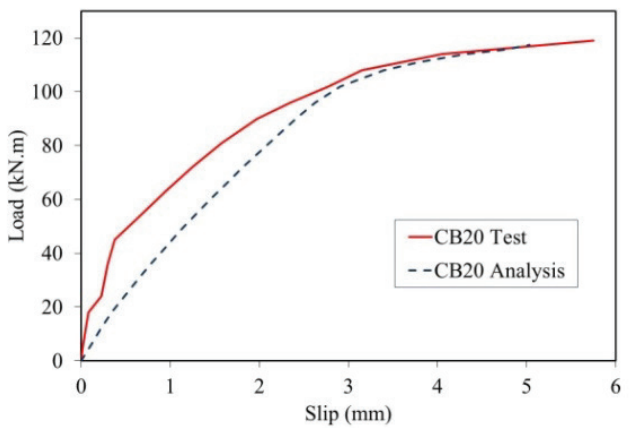

(c) CB20

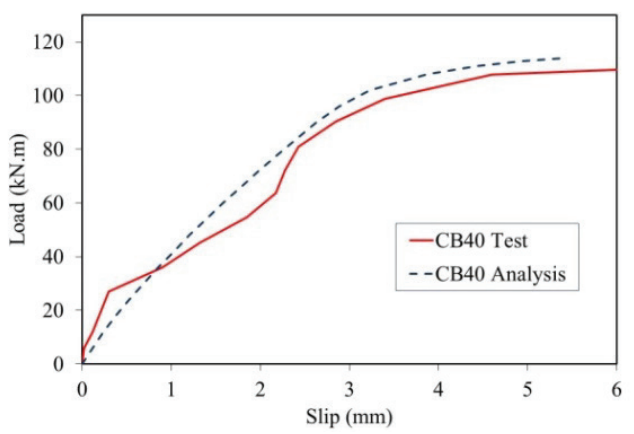

(e) CB40

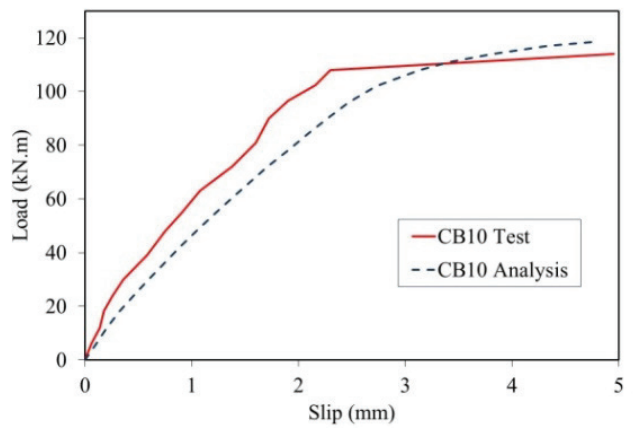

(b) CB10

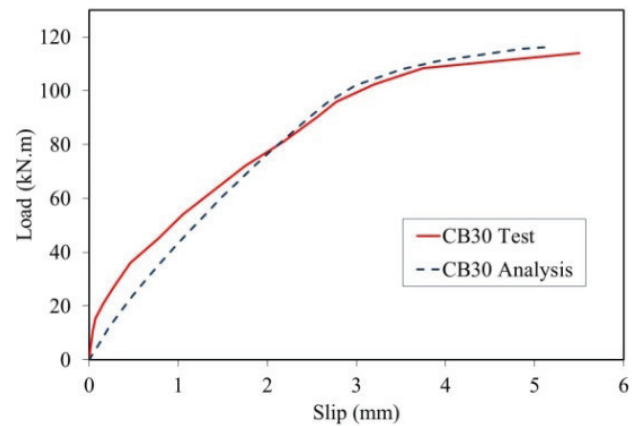

(d) CB30

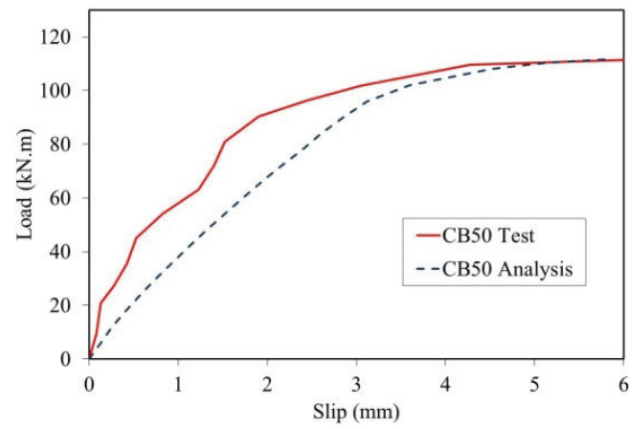

(f) $\mathrm{CB} 50$

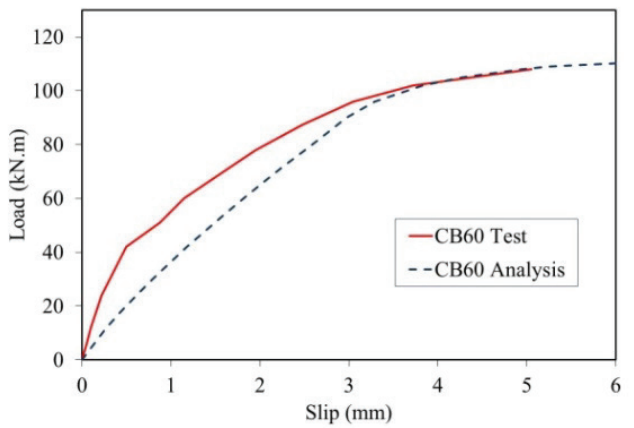

(g) CB60

Figure 10. Comparison of the load-slip curves.

\subsection{Crack width}

Tight control of cracks is normal in bridges; therefore it is necessary to investigate the effect of stud corrosion on the width of cracks. The width of a crack in a concrete slab is decided by two slips, namely the slip between the steel beam and concrete slab and the slip between the reinforcement and concrete. The maximum crack width-load curves obtained from the 
test results are compared with the analytical model predictions in Figure 11. It is seen that the analytical model predictions generally agree well with the test results when the crack width is above $0.2 \mathrm{~mm}$. This

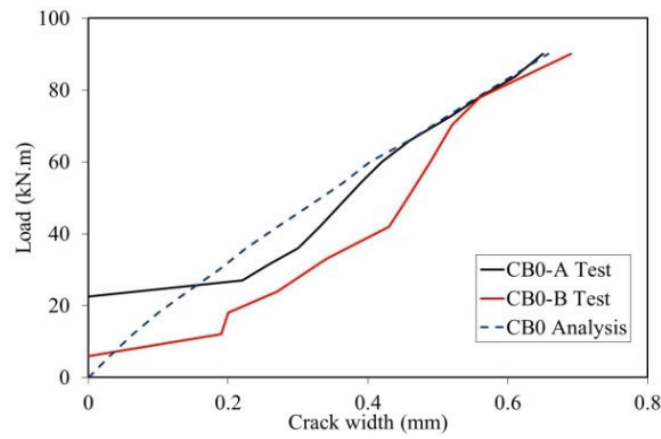

(a) $\mathrm{CB} 0$

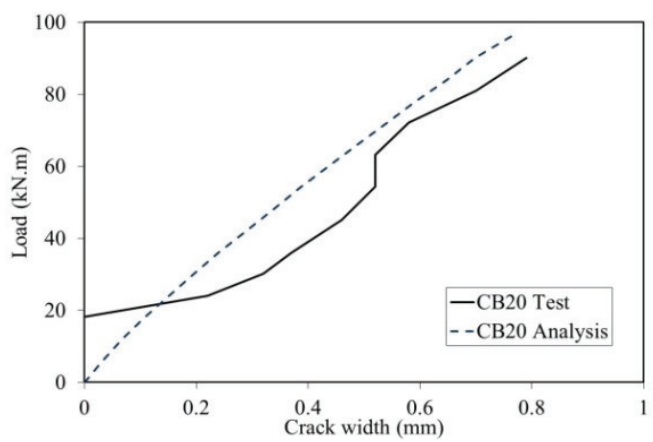

(c) CB20

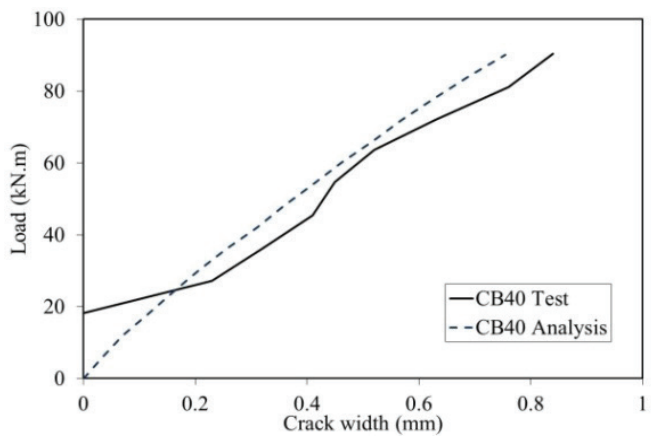

(e) CB40 is expected because there is no crack in the test specimens at the lower load level in the test. However, the analytical model provides a prediction of crack width when the crack width is not negligible.

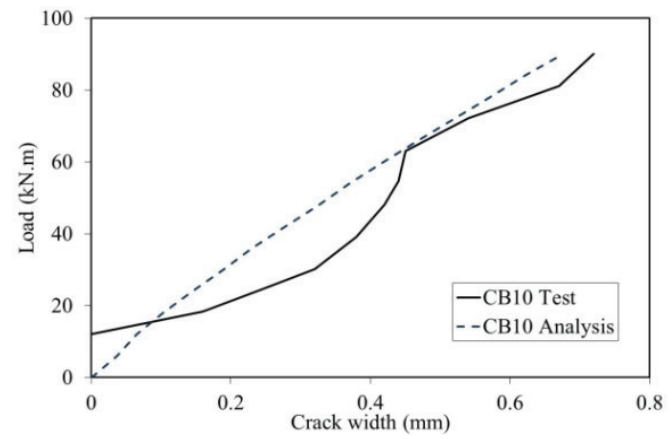

(b) CB10

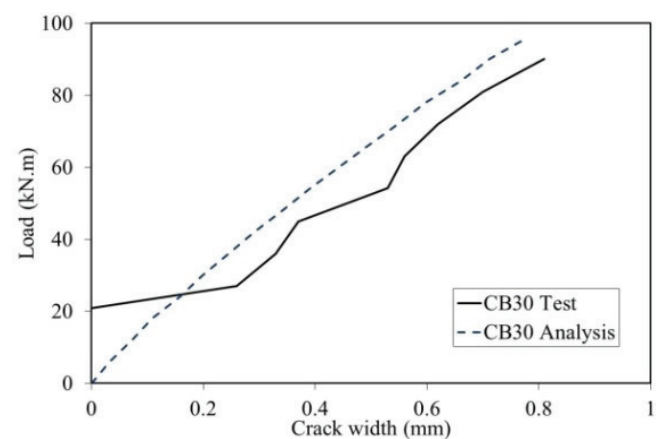

(d) CB30

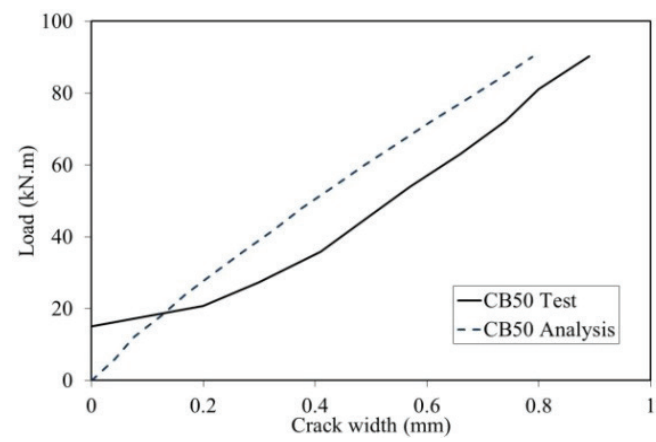

(f) CB50

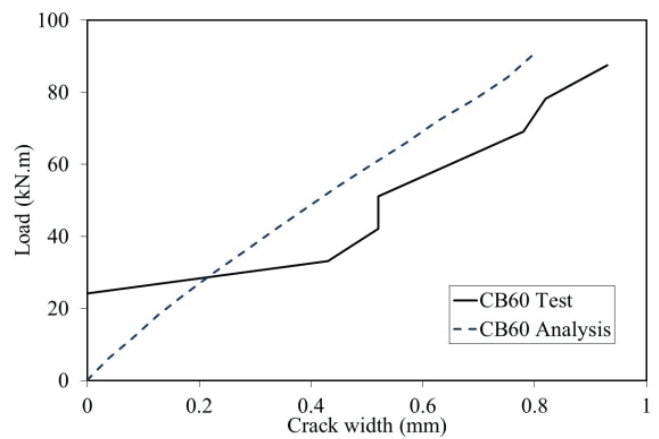

(g) CB60

Figure 11. Comparison of crack widths. 
The contribution of the two slips $\left(\mathrm{s}_{1}\right)$ and $\left(\mathrm{s}_{2}\right)$ to the width of cracks was analyzed, and the results are shown in Figure 12. It is seen that the contribution of the slip between the steel beam and the concrete slab (width-2) is $75-95 \%$, while the contribution of the slip between the longitudinal reinforcing bar and concrete (width-1) is $5-25 \%$. The comparison indicates that the contribution of slip between the steel beam and the concrete slab is dominant. When the corrosion rate of the studs increases, the contribution percentage of width-2 further increases, as shown in Figure 12.

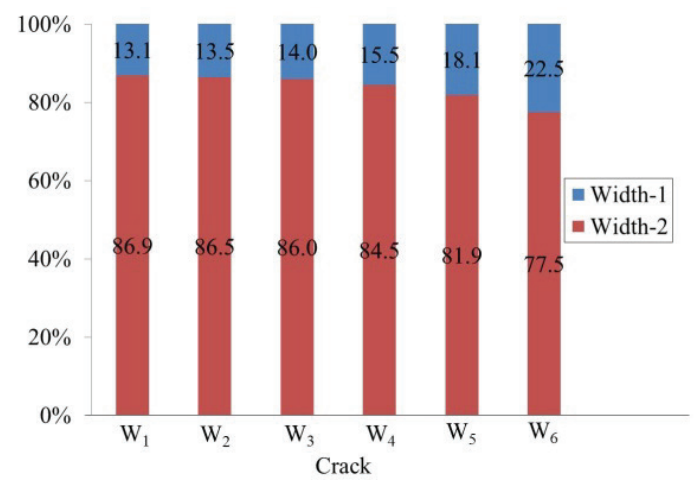

(a) $\mathrm{CB} 0$

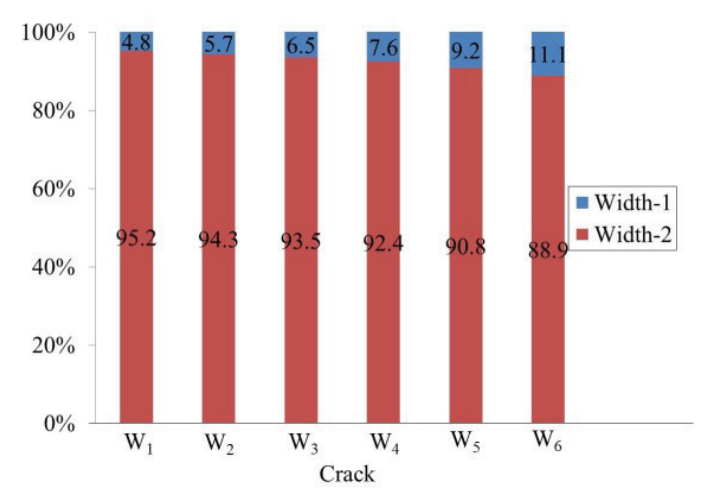

(b) $\mathrm{CB} 60$

Figure 12. Contribution of slips to the crack width.

\section{CONCLUSIONS}

Experimental investigation was carried out to study the effect of stud corrosion on the behavior of a composite beam under hogging moment. It was shown that the deflection and slip between steel beam and concrete slab increase as the corrosion rate increases. However, the effect of stud corrosion on the ultimate strength of the composite beam is relatively small. An analytical model was developed to further study the effect of stud corrosion. Predictions of failure mode, ultimate strength, deflection, slip between the steel beam and concrete slab, and the crack width from the analytical model agree with the test results with reasonable accuracy. It is shown that the slip between the steel beam and the concrete slab makes the dominant contribution to the crack width.

\section{ACKNOWLEDGMENTS}

The research described in this paper was supported by a grant from National Key Technology R\&D Program (2011BAJ09B03), China.

\section{REFERENCES}

Balakrishnan, S., \& Murray, W. (1988). Concrete constitutive model for NLFE analysis of structures. Journal of Structural Engineering-ASCE, 114(7), 1449-1466.

Bertoa, L., Simionib, B., \& Saettab, B. (2008). Numerical modelling of bond behaviour in RC structures affected by reinforcement corrosion. Engineering Structures, 30(7), 1375-1385.

CEB-FIP. (1998). CEB-FIP Model Code 1990. London: Thomas Telford Services Ltd.

Eurocode 4. (2004). EN 1994-1-1: 2004. Design of composite steel and concrete structures: Part 1-1-General rules and rules for buildings, Brussels, Belgium: European Committee for Standardization.

Fabbrocino, G., Manfredi, G., \& Cosenza, E. (2000). Analysis of continuous composite beams including partial interaction and bond. Journal of Structural Engineering-ASCE, 126(11), 1288-1294.

Jiang, A.-Y. (2014) Mechanical performance research of steel-concrete composite beams based on durability (Ph.D. thesis). Zhejiang University, Zhejiang.

Liang, Q. Q., Uy, B., Bradford, M. A., \& Ronagh, H. R. (2004). Ultimate strength of continuous composite beams in combined bending and shear. Journal of Constructional Steel Research, 60(8), 1109-1128.

Loh, H. Y., Uy, B., \& Bradford, M. A. (2004). The effects of partial shear connection in the hogging moment regions of composite beams: Part IExperimental study. Journal of Constructional Steel Research, 60(6), 897-919.

Manfredi, G., Fabbrocino, G., \& Cosenza, E. (1999). Modelling of composite beams under negative bending. Journal of Engineering Mechanics-ASCE, 125(6), 654-662.

Navarro, M. G., \& Lebet, J. P. (2001). Concrete cracking in composite bridges: Tests, models and design proposals. Structural Engineering International, 2001, 184-190.

Nie, J. G., Cai, C. S., \& Wang, T. (2005). Stiffness and capacity of steel-concrete composite beams with profiled sheeting. Engineering Structures, 27(7), 1074-1085. 
Nie, J. G., Fan, J. S., \& Cai, C. S. (2008).

Experimental study of partially shear-connected composite beams with profiled sheeting.

Engineering Structures, 30(1), 1-12.

Ramm, W., \& Elz, S. (1996). Behaviour and cracking of slabs as part of composite beams in regions with negative bending moments. Proceedings of an Engineering Foundation Conference, ASCE, Reston, VA: ASCE. 871-86.
Ryu, H. K., Chang, S. P., Kim, Y. J., \& Kim, B. S. (2005). Crack control of a steel and concrete composite plate girder with prefabricated slabs under hogging moments. Engineering Structures, 27(11), 1613-1624.

Wang, Y. C. (1998). Deflection of steel-concrete composite beams with partial shear interaction. Journal of Structural Engineering-ASCE., 124(10), 1159-1165. 